\title{
Exploring the Path of Rural Tourism in China_—_Taking Yuanjia Village in Shaanxi as an Example
}

\author{
Zhenghai $\mathrm{Wu}^{1}$ \\ ${ }^{1}$ Xi'an Administration College, China \\ Correspondence: Zhenghai Wu, Xi'an Administration College, Xi'an 710054, China.
}

Received: December 23, 2019

Accepted: January 19, 2020

Available online: February 10, 2020

doi:10.11114/aef.v7i2.4709

URL: https://doi.org/10.11114/aef.v7i2.4709

\begin{abstract}
Implementing the strategy of revitalizing the countryside is a major decision-making arrangement made by the Chinese government, and it is the general leader of the work of "agriculture, rural areas and farmers" in the new era. This article aims at rural tourism under the background of urban-rural coordination and rural revitalization. Taking Yuanjia Village's rural tourism as an example, it summarizes the basic practices of rural tourism development in Yuanjia Village. Based on the practical experience of rural tourism development in Yuanjia Village, it proposes the development of rural tourism. The overall idea is that the successful mechanism of Yuanjia Village's development of rural tourism lies in: Cohesion and courage are the primary prerequisites for the development of rural tourism; integrating resources and creating characteristics are the basic conditions for the development of rural tourism; sharing benefits and co-governance is rural Fundamental guarantee for tourism development; integration of cultural tourism and cultural people is the inner soul of rural tourism development.
\end{abstract}

Keywords: rural revitalization, rural tourism, resource integration, benefit sharing, Yuanjia Village

\section{Introduction}

The implementation of the strategy of rural rejuvenation is a major decision-making plan made by the Chinese government and the general leader of the work of "agriculture, rural areas and farmers" in the new era. Guided by the policy, all parts of the country are actively exploring new development paths for rural revitalization. Although the specific path of rural rejuvenation varies and has its own characteristics, the objective facts of the vigorous development of rural tourism in China in recent years have told us that the development of rural tourism is an important way to achieve rural rejuvenation. Scholars such as Liu Qi and Hu Angang believe that rural tourism is "the third entrepreneurship of Chinese farmers" since the reform and opening up (Liu Qi, 2016), and "the third largest among Chinese farmers after the household responsibility system and township enterprises" Invention (Hu Angang, Wang Wei, 2017). It is of great significance and value to deeply study the development of rural tourism in China.

In recent years, the research results of Chinese rural tourism in academic circles have been rich. Guo Xu, Chen Jian and others believe that rural tourism is a leisure and entertainment activity that meets people's hometown and nostalgic needs with its unique rural scenery and local culture with the rapid economic and social development and the general improvement of people's living standards in recent years (Guo Xu, Chen Jian, 2009). At present, China's rural tourism has entered a "golden period" across development, but the problems existing in its development should cause sufficient attention. The problems are mainly manifested in the following aspects: first, the characteristics of rural tourist attractions are not obvious, the tourism products are relatively single, lack innovation, and the homogenization is serious (Guo Xu, Chen Jian, 2009); second, the infrastructure of rural tourist attractions is not perfect, The supporting facilities are not complete, the management level and the professional quality of the employees need to be improved, extensive operation, and the efficiency is not high (Song Dongning, Zhao Yuanfei, 2019); Third, the rural tourist attractions use too many modern element symbols and urban element symbols, The connotation of folk culture is insufficient. "If the essence of rural tourism is eroded by modern urban culture, that is to say, farmers have abandoned traditional rural culture in rural tourism and replaced it with urban culture, and rural tourism will not be attractive to urban residents. "Re-existence" (Zhao Chenghua, 2018); Fourthly, the development and operation of rural tourism focuses on short-term benefits, lack of scientific management, low-end products are flooded, vicious competition continues, and resource protection is weak (Zhao Chenghua, 2018; fifth, government Government management 
mechanisms to support rural tourism development are not coordinated, policies support Support and safeguard measures need to be further improved (Yu Fawen, 2017); Sixth, the local residents 'participation and benefit distribution issues can only fully respect the objective inevitability of the original residents' full participation in rural tourism development, and establish scientific and reasonable management and economic benefits distribution Mechanism can truly stimulate and release the original potential of rural tourism development (Zhao Chenghua, 2018). Some scholars have put forward highly targeted suggestions on the path of rural tourism development: Deeply digging the cultural connotation of local tourism resources and highlighting rural cultural characteristics are The key to the development of rural tourism (Han Zhenhua, Wang Song, 2009). The development of rural tourism must overcome the tendency of simplification of the development model and the tendency of urbanization of rural culture. It is necessary to fully explore the cultural connotation of rural tourism and fully reflect the characteristics of rural local culture; rural tourism development We must adhere to both development and protection, follow the principle of "protection in development, develop in protection", revitalize traditional villages and retain traditional culture, but not blindly, passively or intactly preserve the traditional elements. Organic integration with modern functions Wu Bihu, 2016); the government should establish a coordinated coordination mechanism for rural tourism development, increase support for infrastructure construction and investment and financing support, strengthen grassroots government linkages, standardize rural tourism management, and promote the development of regional tourism; rural tourism scenic spots should pay attention to Detailed and intelligent services, improve the dynamic supervision system, track and monitor the details of management, and meet the needs of tourists' personalized and diversified high-quality needs (Zhang Li, Meng Cheng, 2019). In short, there are a large number of papers on the role of rural tourism, Research has been carried out on development models and paths, driving mechanisms, transformation and upgrading, etc., which provides useful theoretical references for further research on rural tourism development, but few articles have theoretically analyzed the successful practices of rural tourism development in a specific region of China. Summary of experience. The theory comes from practice, and practice needs to be upgraded to theory. In view of this, this article aims at rural tourism under the background of urban and rural coordination and rural revitalization. Taking rural tourism in Yuanjia Village, Liquan County, Shaanxi Province as a specific case, a qualitative analysis and The combination of quantitative analysis The practice of village tourism is combed, trying to reveal the successful mechanism of rural tourism development in Yuanjia Village, with a view to providing possible reference for the development of rural tourism in China.

\section{The Basis and Practice of Rural Tourism Development in Yuanjia Village}

\subsection{Regional Overview}

Yuanjia Village is located in the hinterland of Guanzhong Plain, Shaanxi Province. It is located under the world-famous Tang Taizong Li Shimin Zhaoling Jiuling Mountain to the north of Yanxia Town, Liquan County, Shaanxi Province. The Guanzhong Ring Road passes by the village side, less than ten minutes away from the Fuyin Expressway and 312 National Road. Thirty-five kilometers from Xi'an Xianyang Airport, the transportation is very convenient, the tourism resources are abundant, and the location advantage is obvious. The village has a total of 69 households and is a natural village with a registered population of 282 people. In recent years, Yuanjia Village has been rated as China's 4A-level scenic spot, and won the honors of China's Top Ten Beautiful Villages, China's Top Ten Most Charming Leisure Villages, Famous Tourist Villages with Chinese Characteristics, China Rural Tourism Demonstration Villages, and China's Top Ten Well-off Villages. title.

\subsection{Historical Basis of Rural Tourism Development in Yuanjia Village}

From the 1970s to the beginning of the 21st century, the development of Yuanjia Village went through two important stages.

In the first stage, from 1970 to 1978, land preparation was carried out to solve the problem of food and clothing. Prior to this, Yuanjia Village was a locally known backward village. A local proverb can roughly reflect the situation in Yuanjia Village at the time: "There is no cattle in the cultivated land, no lights and oil, no cadres in their early stages, food depends on resale, life depends on relief, and money depends on loans." From 1958 to 1970, During the year, the village did not pay a pound of grain to the state, and the villagers did not share a penny from the production team. The total collective accumulation of the village was only 5,700 yuan, but the external debt was 10,600. Thirty-five team captains were changed between the twelve years, but his work was no improvement. In 1970, Guo Yulu was elected as the thirty-sixth team captain. Under his leadership, the whole village vigorously developed grain production. Through digging slopes, filling trenches, and drilling wells and fertilizing, the 400 acres of sloping land in the village became flat and neat, and the annual output per acre was from 1970 One hundred and sixty pounds per year have been increased year by year, and the maximum output has reached 1,650 pounds. The increase in output not only solves the problem of eating in Yuanjia Village itself, but also households have surplus grain, and each person contributes more than 1,000 kilograms of grain to the country every year. By vigorously developing agricultural production, Yuanjia Village not only 
solved the problem of food and clothing, but also became a benchmark for collective economic development and a banner for agricultural development in the province.

In the second stage, from 1978 to 2005, we will do a good job in the development of village-owned enterprises. After the reform and opening up, Yuanjiacun's leading thinking was to develop village-run enterprises, transfer surplus labor, accelerate the process of industrialization, adjust the agricultural industrial structure, and increase farmers' income. Under the leadership of the village party secretary Guo Yulu, the village has built village-owned enterprises such as white ash kiln, brick kiln, and cement prefabrication factory. After continuous renovation and upgrading of the cement plant invested in 1983, the annual output value was stable at about 800,000 yuan, accounting for $56 \%$ of the total industrial and agricultural output value of the village, and became a pillar industry of the village in the 1980s. In 1988, Yuanjia Village set up an agricultural and industrial company, and the village-owned industry showed a good development momentum, which further strengthened Yuanjia Village's confidence and courage to develop a collective economy. In 1990, the village collective invested 4.6 million to build a number of village-run enterprises such as ferrosilicon plants, printing plants and sponge factories. At the same time, around the development of the enterprise, a car transport team and a construction team were established, and a commercial service department was established. The rapid development of the industrial economy has not only increased the income of the villagers, but also made the village collective economy smoother. In October 1992, the village collectively widened the development area and increased the investment scale, so that the original village agricultural and industrial company quickly developed into a collection of building materials, catering, tourism, transportation services, real estate and film and television, with total assets of one billion yuan. The development of a large group company, Yuanjia Village, successfully integrated into the Greater Xi'an Economic Circle, and realized the transition from stable villages in agriculture to rich villages in industry. The annual per capita net income of villagers increased from 29.6 yuan in 1970 to 8,600 yuan in 2000, and the collective assets of the village reached 680 million, making it a well-known small village in the country.

\subsection{Main Practices of Rural Tourism Development in Yuanjia Village}

At the beginning of the 21st century, Yuanjia Village began to explore the development of rural tourism. After 2000, with the introduction of the state's shutdown policy for small cement plants, the development of village-owned enterprises fell into a hovering stage, and Murakami was unable to find a new path for development. In 2006, Yuanjia Village quickly responded to the call of the Liquan County Party Committee and County Government to vigorously develop rural tourism. Many parties sought three new ways to start a business. After repeated choices, they finally decided to rely on the unique human resources and develop rural folk tourism. In 2007, Yuanjia Village highlighted the characteristics of Guanzhong folk culture and traditional farming, invested 35 million yuan in the tourist area, and successively built more than 100 Kangzhuang folk customs that integrate Guanzhong workshops, Guanzhong folk experience, Guanzhong snacks, and Guanzhong juggling. Street shops have created the famous "Guanzhong Impression Experience Site-Yuanjia Village Farming Folk Culture" tourism brand. On the north side of Folk Street, an entertainment street covering 36 shops including Guanzhong Inn, various bars, coffee houses, academies, and international small commodity supermarkets has been successively formed, forming a rich main content, distinctive cultural features, and colorful content. Rural tourism is favored by domestic and foreign tourists. At the same time, in accordance with the idea of "one household, one characteristic, one household, one brand", 56 quaint Guanzhong farmhouses were gradually built to provide tourists with leisure tourism services such as catering, accommodation, chess and cards, fruit and fruit picking, and rural experience. Let visitors experience the relaxed and idyllic ecological life. In 2012, Yuanjia Village aimed at the development prospects of tourism agricultural products. Through the establishment of a joint-stock company, it integrated tofu, yoghourt, glutinous rice, and spicy seeds and other special agricultural and sideline products in the food street. Tofu and other products are in short supply, with an average annual income of more than 60 million, filling a gap in the tourist product market in Yuanjia Village. From 2014 to 2016, Yuanjiacun invested another 400 million yuan to build nine projects including Qinqiong Hotel, Guanzhong Ancient Town, and Guanzhong Folk Inn to extend the industrial chain. After more than ten years of development, the scale of Yuanjia Village's collective economy has grown unprecedentedly. In 2015, the per capita net income of the entire village reached 38,000 yuan, and the total assets of the village collective reached 220 million yuan, including 15 million current assets and 205 million fixed assets. In Yuanjia Village, more than 3,000 entrepreneurs have been employed, driving nearly 10,000 people in the surrounding tourism industry. In the next step, Yuanjia Village will follow the idea of "one village and ten villages for common prosperity and common development" to enlarge and strengthen food processing enterprises, continuously improve the quality of rural tourism, and let more people enjoy safe and reliable green food and experience. Come to relax country life.

\section{The Practice of Rural Tourism Development in Yuanjia Village}

Through in-depth research, we summarized and summarized the main methods of rural tourism development in Yuanjia Village. 


\subsection{Adhere to the Original Intention of the People and Work Together for Prosperity and Prosperity.}

Ideas determine practices, ideas determine the way out. At the beginning of rural tourism development in Yuanjia Village, the ideas and requirements of village cadre Guo Zhanwu can be conveyed to every cadre, every workshop, and every villager; now the development is relatively mature, and the village party secretary is mainly responsible for the development direction of the village and the cadre team Management. Regarding Yuanjia Village's success in developing rural tourism in these years, Guo Zhanwu believes that rural tourism is indeed a successful way to explore the development of Yuanjia Village, but it is not the core of the development of Yuanjia Village, nor is it the ultimate goal. He believes that to build a century-old Yuanjia Village, the core lies in industrial development. From 2007 to the present, the industrial development of Yuanjiacun has continuously expanded and increased the chain, from the original Guanzhong folk custom tour to the rural holiday tour, and the agricultural and sideline product industry chain. Step by step, village cadres in Yuanjia Village constantly explore new ways to lead villagers to get rich together. It is precisely because the original intention of the cadres of Yuanjia Village is to make the villagers get rich together and continue to get rich. Therefore, the operation mode of Yuanjia Village is very different from that of other villages. The idea of a cadre in Yuanjia Village is simple and simple, that is, to make farmers make money and to make the industry develop longer. Such an original intention and practice are exactly in line with the pursuit of the majority of the villagers and the policy requirements of the state to promote the development of the rural leisure tourism industry and allow farmers to fully participate and benefit. It should be said that in rural China, the farmers and rural areas are fully understood. Yuanjia Village is one of the best in integrating the tourism industry with the interests of farmers.

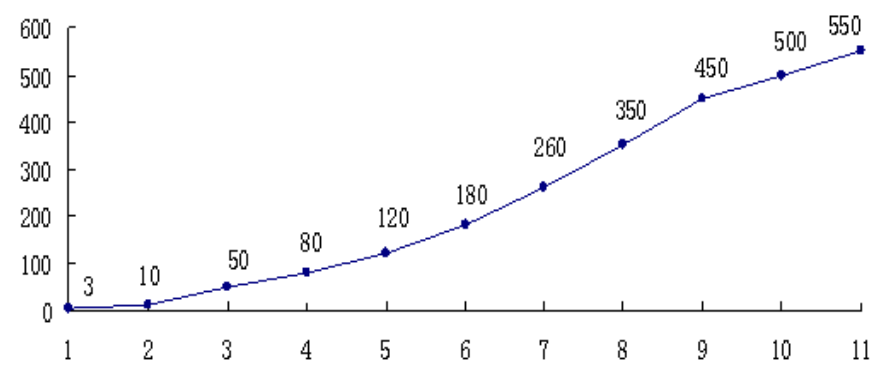

Chart 1. Number of Tourists Received in Yuanjia Village 2007-2017 Unit: 10,000 people

\subsection{Innovate the Governance Mechanism, and Build and Share Vitality}

The core of the Yuanjiacun model lies in strengthening the collective economy and achieving common prosperity. In order to achieve this goal, Yuanjia Village took rural tourism as the starting point and changed collective resources, land resources, and real estate resources into capital. The original idle factory buildings and fixed assets were used as capital. The village collectively invested 20 million yuan and was incorporated. Yuanjiacun Tourism Development Co., Ltd. quantifies the company's equity to 62 people in the village at 200,000 yuan per share, collectively holding $38 \%$ of the shares, and the people holding $62 \%$ of the shares. At the same time, it starts with the transfer of collective land in the village and starts with ownership and contracting rights. On a constant basis, at a price of 40,000 yuan per mu, villagers voluntarily transferred 572 acres of land management rights to the village collective, realizing the transformation of resources to assets; and in accordance with the principle of voluntariness and spontaneity, according to the total valuation of villagers' houses $10 \%$ As a capital investment into the Yuanjia Tourism Development Company, the fixed resources are turned into operating living assets, laying a solid material foundation for the practice and exploration of common prosperity. Common prosperity is not a big pot rice, and collective economy is not an iron rice bowl. On the management model, Yuanjiacun actively promotes distribution reform, implements shareholding operation, stimulates the endogenous motivation of the masses to start businesses with a reasonable and effective distribution method, and absorbs five types of shares: basic shares, mixed shares, cross-shares, regulatory shares, and restricted shares. The village and the surrounding people have taken shares, turning farmers into shareholders. Adopting the participation of the whole people, voluntary participation in shares, early entry with less money, and how much money is taken into account, taking care of small households, and restricting large households, realizes that you have me and you have me, and promotes the balanced development of collective and peasant household interests. Yuanjia Village has big dreams. What we have to do is a century-old Yuanjia Village. The starting point and end point are to help farmers get rich together. Therefore, in the operation of Yuanjiacun, it seeks for a sustainable and sustainable industry, and continuously adjusts according to the actual situation, in pursuit of long-term industrial development and common prosperity. 
Table 1. Comparison before and after the development of rural tourism in Yuanjia Village

\begin{tabular}{|l|l|l|}
\hline Indicator & In 2007 & In 2018 \\
\hline Number of households & 62 households & 69 \\
\hline Household population & 286 people & 282 \\
\hline Farmhouse & 5 households & 62 \\
\hline Featured Theme Blocks & 1 & 10 \\
\hline Shop & 1 household & 623 \\
\hline Farmers cooperatives & no & 17 \\
\hline Local employment in tourism & Less than 100 people & More \\
\hline Number of tourists & 30,000 person-times & 5.5 \\
\hline Shareholders & no & 1060 \\
\hline Farmers' equity funds & no & 80.36 \\
\hline Per capita net income of farmers & 16,000 yuan & 83,000 \\
\hline Village collective income & 180 million yuan & 520 million yuan \\
\hline
\end{tabular}

Data source: Yuanjia Village Village Committee

\subsection{Promote Industrial Integration and Carefully Cultivate the Industrial Chain}

Yuanjia Village is an authentic Guanzhong village. There are no particularly prominent tourism resources. The reason why they can make rural tourism to the present level is to adapt to local conditions, integrate resources, and create characteristics. The theme of rural tourism in Yuanjia Village is Guanzhong folklore but not others. As Guo Zhanwu, a cadre of Yuanjia Village, said, "Why do n't we do red tourism or Tang Zhaoling because those are not directly connected to our lives. What we have to do is authentic rural life in Guanzhong. What we say, our clothes Many of our things are part of the folk customs in Guanzhong. We can do this thing, and we cannot do anything else. " Focusing on the theme of Guanzhong's folk and rural tourism, Yuanjia Village integrates two resources to serve one demand and achieves win-win results for multiple parties. Specifically, in terms of the excavation and integration of tourism resources, Yuanjia Village continuously excavates and integrates two types of resources outside the village and uses tourism resources such as cuisine, customs, dialects, costumes, farming tools, buildings, and scenes with traditional farming cultural characteristics. The original characteristics of the local characteristics are reproduced. Through a series of services such as tasting food and feeling the local style, it provides rural tourism consumers with the best travel experience of "returning to the local area, tasting the local style, reminiscing the nostalgia, and relaxing", which greatly meets the rural Tourists 'deep-rooted needs and potential needs for" hometown, local customs, nostalgia, delicious beauty, and body and mind "meet the needs of consumers while achieving multi-win and common prosperity for various operators outside the village. .

\subsection{Strengthen Moral Construction and Inherit Civilization and Harmony}

Yuanjiacun has a common tenet: farmers defend food safety! In Yuanjia Village, this is by no means a slogan, but a real action. The primary guarantee is the industrial linkage mentioned earlier, which makes a large number of raw materials from rural areas active and ensures the result of food safety from the source. On the other hand, it comes from the moral constraints imposed by collectivism in Yuanjia Village. In Yuanjiacun's shop, we can see the guarantee commitments of each merchant in a most primitive way to ensure their food safety. In addition to industry interaction as the most powerful supportive backing, the collective shareholding system of "you have me, you have me" has formed a strong supervision system, coupled with a simple way of commitment, people can't help but believe it! So good word of mouth slowly formed. Another thing that must be explained is that in addition to the party branch and village committee in the village, Yuanjia Village also set up Mingli Hall to invite high-profile people to preside over, handle various contradictions in the village, and organize villager education. The establishment of the Mingli Church in Yuanjia Village has played a key role in maintaining the harmony between villagers and villagers, and between villagers and tourists. Through moral education, it has virtually resolved the contradictions between tourists and locals that cannot be resolved 
in many scenic spots. . This inherited the moral education of traditional local civilization, nourished civilization and courtesy, and enhanced harmony and strength. The success of Yuanjia Village in rural tourism and rural rejuvenation is more or less related to its rural and civilized governance style, and its moral qualities and pioneering spirit. If Yuanjia Village is a management miracle, The core soul that accomplishes this miracle lies in Mingde!

\section{The Successful Mechanism of Rural Tourism Development in Yuanjia Village}

\subsection{Cohesion and Courage Are the Prerequisites for the Development of Rural Tourism}

Practice has proved that the strength of rural grassroots party organizations is directly related to the efficiency of the implementation of the rural revitalization strategy. The key to a strong village is to have a good branch. Therefore, people often say: "The key to the prosperity of the countryside depends on the branch; the masses look at the party members, the party members look at the branch, and the branch looks at the branch secretary." The successful way for Yuanjia Village to develop rural tourism lies in the co-ordination of party building and development, and strong development of the party building. Many people think that Yuanjia Village is similar to other "snack villages", but in fact, the success of Yuanjia Village is a typical example of the village cadres leading the villagers to become rich together. Only by seeing and recognizing this can we succeed in grasping the success of Yuanjia in developing rural tourism The key to this is a good illustration of the importance of good leaders for rural development. The development of Yuanjia Village in recent years is inseparable from the correct leadership of the village cadres, especially the village party secretary Guo Yulu and Guo Zhanwu played an important leading role in the development of Yuanjia Village. Without the enthusiasm and development foundation formed by the Party Secretary Guo Yulu to lead the villagers to prepare land and develop enterprises, it would be difficult to have the spirit of unity, courage, and courage to explore in Yuanjiacun today. Without the Party Secretary Guo Zhanwu Folks working hard to explore new paths and pursue common prosperity and the original intention and public will make it difficult for Yuanjia villagers today to develop rural tourism and build beautiful countryside.

\subsection{Integrating Resources and Creating Characteristics Are the Basic Conditions for the Development of Rural Tourism}

At present, the way out for China's agricultural development lies in the system and mechanism, the foundation lies in quality and characteristics, and the key lies in value-added and integration. In a market economy, the selling point is the point where the interests of both the supply and the demand combine. Only the selling point will have the market, and the selling point will make money. The success of rural tourism in Yuanjia Village is, in a sense, the success of finding the selling point of rural tourism, and finding the interests of both sides of rural tourism supply and demand. In other words, Yuanjiacun captured the needs of rural tourists and satisfactorily met the needs of rural tourists, thus realizing the good benefits of developing rural tourism. Yuanjia Village's main efforts in developing the selling point of rural tourism are: around the theme of rural tourism in Guanzhong, Yuanjia Village integrates two resources, serves one demand, and achieves win-win results for multiple parties. The success of Yuanjia Village's development of rural tourism lies in the coordination of resources and markets, and the creation of large markets with good ideas. Throughout the recent development of Yuanjia Village, they followed the laws of the market economy and reorganized farmers to realize the process of evolution from agriculture to industry and industry to the integration of three industries. The transformation and breakthrough of collective economic development in Yuanjia Village changed both The traditional development model in rural areas has realized the "transmutation" of development quality from low to high, development path from narrow to wide, and development benefits from weak to strong.

\subsection{Sharing Benefits and Working Together Is the Fundamental Guarantee for the Development of Rural Tourism}

The core feature of Yuanjiacun's rural tourism model is the development and growth of the village's collective economy. The secret behind it is the decentralization of the collective economy. The diversified share structure of "you have me and you have me" effectively realizes collective and individual interests. The high degree of integration has fully mobilized the initiative and creativity of stakeholders such as cadres, the masses, and merchants, and formed a new model of rural revitalization of "shared, shared, co-constructed, co-rich, and co-managed". The success of Yuanjia Village's development of rural tourism lies in the co-ordination of interests and governance to stimulate great energy with a good mechanism. Using the form of villagers' equity participation, the villagers of Yuanjia Village formed a community of interests. The quality of each business is directly related to the interests of everyone. Therefore, the business of the neighbors is also their own business. As long as the business is good, no matter which one is good, everyone makes money and is happy. And when the interests are tied to everyone, each operator constitutes a community of destiny. The quality of Yuanjiacun is related to everyone, and the true collectivism is formed by the binding of vital interests. Yuanjia Village was jointly built by the villagers. The villagers walked in Yuanjia Village. Maybe the stones on the road were made by me. Maybe the walls of that house were made by me. So the complete composition of this village is the complete composition of the villagers. The plants and trees in the entire village are shareholdings and are owned by everyone. Everyone in Yuanjia Village has a strong sense of belonging. The quality of Yuanjiacun is related to everyone. This kind of belonging collectivism makes people form a community of 
responsibility. Strong collectivism and a sense of collective honor have formed a natural supervision system, which makes everyone who has not worked hard nowhere to hide. The villagers of Yuanjia Village themselves have formed a community of honor. In Yuanjia Village, he really did a great job of mobilizing the masses.

\subsection{The Integration of Cultural Tourism and Cultural People Is the Inner Soul of Rural Tourism Development}

Another secret of Yuanjiacun's sudden rise is to rely on traditional culture, make articles around Guanzhong folklore, give full play to the core competitiveness of intangible cultural heritage, focus on Shaanxi snack and pasta culture, take root in the countryside, look at the country, and make independence. Unique tourism + cultural and rural tourism brand. The successful way for Yuanjia Village to develop rural tourism is to achieve overall planning for culture and development, and to create a great tourism with good culture. First, the roots of traditional culture are in the folk and in the countryside. Therefore, based on the countryside, it is easier to restore and promote traditional culture in the locality, and it is easier to create originality and introduce new ones. The second is that the soul of China's outstanding traditional culture is immaterial. These folk arts and customs passed down from generation to generation need to be displayed and inherited. But leaving tourism leaves the space for vigorous promotion and development. The tourism characteristics of China have grown stronger and stronger. The third is development in inheritance and inheritance in development. Through the ruralization of lifestyle, Yuanjia Village followed the concept of "various trees, no lake filling, and less house demolition" in the process of retrofitting the village as old as possible, maintaining the original ecology, reflecting the local customs and promoting With the folk customs, the natural mood of "seeing the mountains, seeing the water, remembering to live in homesickness" has become the biggest feature, realizing the "return to nature" of agricultural products, and the transformation and upgrading of rural culture.

\section{Summary}

The successful mechanism of Yuanjia Village's development of rural tourism lies in the following: the first prerequisite for rural tourism development is to focus on one's heart and be brave in practice; the integration of resources and the creation of characteristics are the basic conditions for the development of rural tourism; Fundamental guarantee; integration of cultural tourism and cultural people is the inner soul of rural tourism development. The practice of Yuanjia Village provides a successful example of the transformation and development of the traditional collective economy to the new collective economy. It also provides such a rural collective economic development case of industrial integration, property rights sharing, village governance, and development sharing. It is better The land has overcome the blindness and decentralization of individual farmers' management, achieved the consistency of the interests of all villagers, avoided polarization, and took the path of common prosperity.

\section{References}

Guo, X. et al. (2019). Status and Countermeasures of Rural Tourism Development in Metropolis_— Taking Nanjing as an Example [J]. Social Sciences in Nanjing, 2009(11).

Han, Z. H. et al. (2009). Research on the Development and Integration of Rural Cultural Tourism Resources [J]. Reform and Strategy, 2009(9).

Hu, A. G. et al. (2017). Rural tourism: a leap from agriculture to service industry [J]. Theoretical Exploration, 2017(4).

Kong, X. Z. (2019). Progress, Problems and Trends in the Implementation of Rural Revitalization Strategy [J]. Studies on Socialism with Chinese Characteristics, 2019(1).

Learning camp in characteristic towns. Yuanjiacun mode-"Six strokes" of Guo Village Chief [DB / OL]. NetEase number. Retrieved from http://dy.163.com/v2/article/detail/CU4LBRNF0518H3VC.html

Liu, Q. (2016). Rural tourism: the third entrepreneurship of Chinese farmers [J]. China Development Watch, 2016(4).

Liu, S. J. et al. (2019). Transformation and upgrading strategies of leisure and tourism-oriented villages under the guidance of the rural complex [J]. Jiangsu Agricultural Sciences, 2019(2).

Ma, S. (2018). Research on the Sustainability of Rural Tourism Development in Yuanjia Village, Xianyang City [D]. Master's Thesis of Gansu Agricultural University, 2018.

Song, D. N. et al. (2019). Problems and countermeasures of developing rural tourism in Harbin [J]. Strategy and Decision, 2019(2).

Wang, Z. M. et al. (2019). Creating rural towns with the concept of rural complex [J]. Cai Zhi, 2019(7).

Wu, B. H. (2016). Traditional Village Protection and Revitalization Based on Rural Tourism [J]. Social Scientist, 2016(2).

Wu, Z. H. (2014). Rural land improvement based on urban-rural coordination [J]. Reference for Economic Research, 2014(34). 
Xi, J. P. (2017). Decided to build a well-off society in an all-round way to win the great victory of socialism with Chinese characteristics in the new era [DB / OL]. Retrieved from Xinhuanet: http: //www.xinhuanet

Yu, F. W. (2017). Motives, Problems and Policy Suggestions for the Development of Rural Tourism in China [J]. Enterprise Economy, 2017(3).

Zhang, J. Z. (2018). Yuanjiacun: 40 years of development pace and reform at the same frequency [N]. Shaanxi Daily, October 18, 2018.

Zhang, L. et al. (2019). Research on Homogeneity in Rural Tourism [J]. Border Economy and Culture, 2019(5).

Zhang, S. Z. (2016). Understand Yuanjiacun [N]. China Tourism News, September 5, 2016.

Zhang, Y. (2018). How to realize sustainable development of rural tourism [N]. Xi'an Daily, July 30, 2018.

Zhao, C. H. (2018). Analysis and Path Choice of Sustainable Development of Rural Tourism [J]. Agricultural Economy, 2018(4).

\section{Copyrights}

Copyright for this article is retained by the author(s), with first publication rights granted to the journal.

This is an open-access article distributed under the terms and conditions of the Creative Commons Attribution license which permits unrestricted use, distribution, and reproduction in any medium, provided the original work is properly cited. 